\title{
New Approach of PCR Technology for IGF-I Evaluation
}

\author{
Ricardo Santander ${ }^{1}$ and Jerzy Trojan*2 \\ ${ }^{1}$ Faculty of Science, National University, Medellin, Colombia \\ ${ }^{2}$ Laboratories Legrand, Bogota, and INSERM U.602, Paris Sud University, Villejuif, France
}

Received: 阱August 27, 2018; Published: 眥 August 31, 2018

*Corresponding author: Jerzy Trojan, Laboratories Legrand, Bogota D.C., Colombia

\section{Introduction}

PCR or Polymerase Chain Reaction is a technique widely used in molecular biology laboratories. Since it was developed in 1983, many procedures use this technique as a basic principle, for example: forensic tests, diagnosis of diseases, phylogenetic studies, identification of mutations, nucleotide sequencing, among others [1-3]. In our procedures of IGF-I diagnostic, we use the techniques of northern blot, western blot, Elisa, immunocytochemistry and cytofluorometry, and the technique of PCR seems still the most rapid and useful in clinical laboratory [4,5] The IGF-I test is among the most important indications for precancerous diagnostic [6]. Therefore, the accessibility of PCR technique giving increased efficiency and rapidity has become a goal to establish a new methodology. The traditional thermal cycler consists of a metal plate or block that has the Eppendorf tubes located at the top, and at the bottom is an electrical device that uses Peltier technology to increase or decrease the temperature according to the requirements of the cycle. There are temperature sensors distributed below the block (Figure 1).

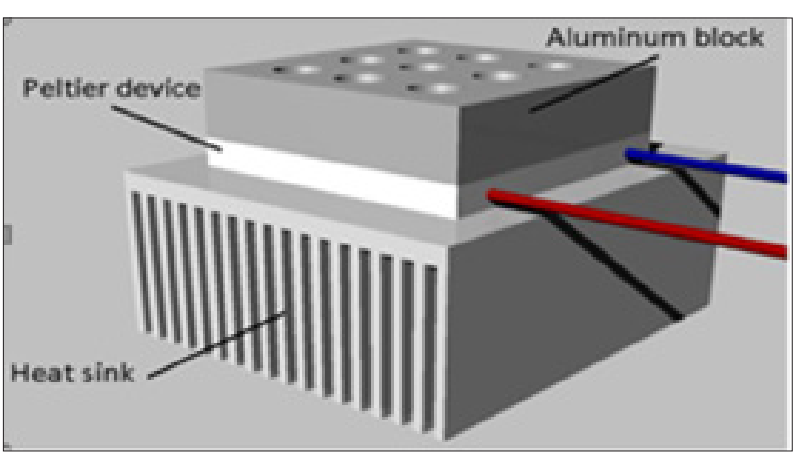

Figure 1: General diagram of a conventional thermal cycler.

For PCR tests, a commercial thermal cycler is relatively expensive. There are several models of low cost thermal cyclers, but they are generally inefficient or inaccurate and also have high energy consumption which is an obstacle for mobile laboratories supported by a limited energy source [7]. Given this challenge, we have developed a low-cost thermal cycler that offers better efficiency with lower energy consumption, an important asset to enable the use of PCR technique in developing countries.

\section{Methodology}

\section{Thermal Cycler with Movement}

This thermal cycler was designed with the purpose of decreasing the time it takes the sample to reach the desired temperatures. To achieve this goal, it was necessary to change the principle of operation of the machine; instead of using chillers and heaters, the machine uses an Arduino board to control a mechanical system composed of two motors, two conveyor belts, two transverse pinions and a tray where the samples are located (Figure 2) [8]. This system introduces and removes the samples in a bath of glycerin hot at $108^{\circ} \mathrm{C}$, the program of the microcontroller constantly monitors the temperature inside the Eppendorf tube, in this way the exact time is used and necessary to complete the reaction.

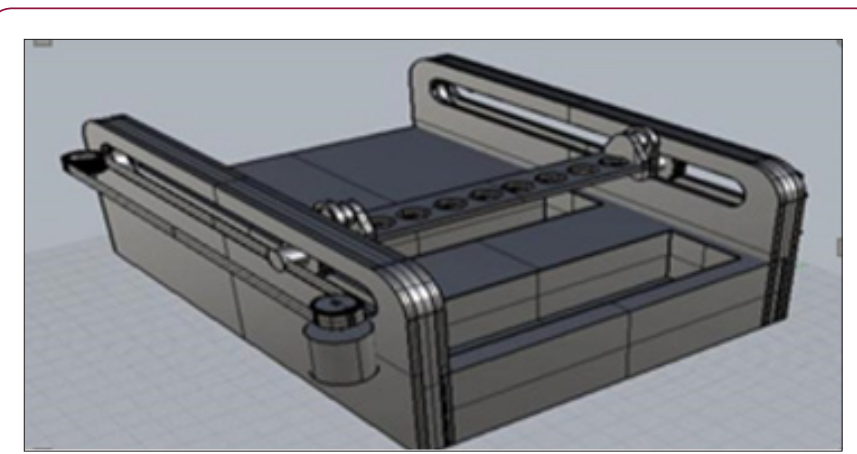

Figure 2: Thermal cycler mechanism with movement. Perspective of the complete machine. See, on the left part of thermal cycler, the pinion coupled to the tray in charge of the translation.

\section{Stages of the Thermal Cycler with Movement}

To go through all the stages of the cycle, this thermal cycler has to constantly monitor the temperature inside the Eppendorf tube. The way in which the thermal cycler complies with each process is described as follows (Figure 3): 


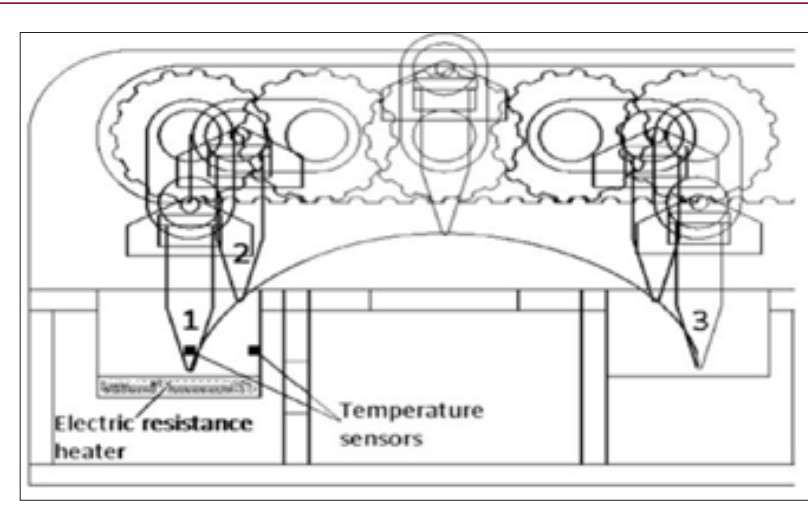

Figure 3: Thermal cycler with movement. Transition movement of the pinion. (1) Denaturation; (2) Extension; (3) Alignment. The electrical resistance should be turned on and off constantly as necessary to maintain the temperature at $108^{\circ} \mathrm{C}$. One of the eight tubes has a temperature sensor inside.

a) Denaturation: The motors rotate to move and submerge the tubes in the bath at $108^{\circ} \mathrm{C}$. The microcontroller must wait until the temperature of the tube reaches $94{ }^{\circ} \mathrm{C}$, when this happens the motors retreat to remove the tubes.

b) Alignment: The motors keep going back until reaching the bath with water at room temperature. The microcontroller must wait until the tube temperature reaches $55^{\circ} \mathrm{C}$, when this happens the motors advance to remove the tubes

c) Extension: The motors advance until submerging the tubes in the hot bath. The microcontroller waits until the tube temperature reaches $72^{\circ} \mathrm{C}$. In this step the reaction is enzymatic therefore it needs to maintain the temperature for a certain period of time. This is achieved by removing and introducing the tube as necessary; when the temperature reaches the lower limit $\left(71^{\circ} \mathrm{C}\right)$, the tube is introduced, and when it exceeds the upper limit $\left(73^{\circ} \mathrm{C}\right)$, the tube is removed. The machine in this step would be constantly seen between positions 1 and 2 of Figure 3.

\section{Results and Discussion}

Several advantages can be highlighted in this new thermal cycler with respect to the traditional model. In this thermal cycler, no specific brands of tubes are needed to work in optimal conditions, since the contact area with the liquid medium is always the maximum. This is also an important factor in increasing the heat transfer rate. This equipment allows a more exact control in the duration of the periods and the temperatures of the cycle, this entails to a saving of time. The only device that has a considerable expenditure of energy in this machine is the electrical resistance, but it is not an important expense compared with the Peltier device of the conventional thermal cycler. Once the bath is hot, the resistance is switched on intermittently for short periods of time each time the temperature decreases, making the expense much lower.

All the materials and electronic devices that are part of the machine are easy to obtain, which makes it perfect for a low-resource laboratory. The PCR of IGF-I using a classical thermal cycler and the thermal cycler with movement are presented below (Figure 4). The timing of classical thermal cycler and a new thermal cycler are as 2:1. The classical thermal cycler took 80 minutes while the thermal cycler with movement took practically 40 minutes. There is a high probability that the time using thermal cycler with movement can be shortened even more - the whole PCR taking about 30 minutes (the work in progress). The new PCR technological approach will serve to measure the expression of other antigens engaged in IGF-I gene therapy [9].

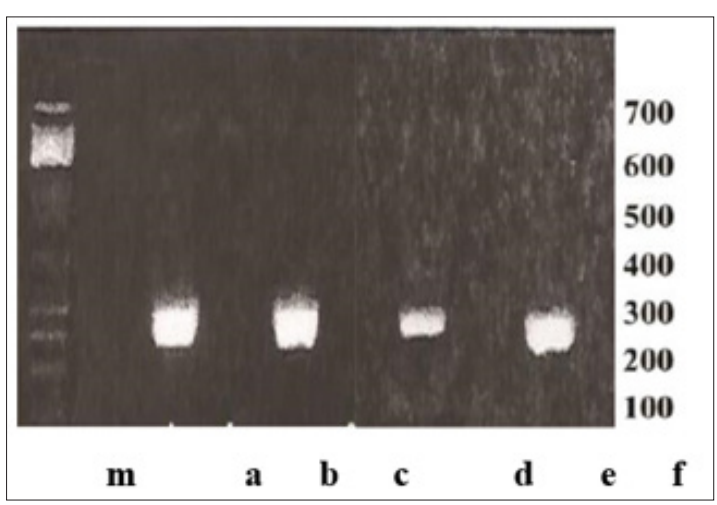

Figure 4: IGF-1 genetic testing using PCR technique [8]. (a, d) DNA of IGF-I using classical thermal cycler; (b,e) control negative sample; (c, f) DNA of IGF-I using thermal cycler with movement; (a) and (c) the results obtained after 80 minutes; (d) and (f) the results obtained after 40 minutes: note that intensity of band (d) is smaller than that of band (f); (m) Marker (PCR markers, Promega corporation). Note: $200-300 \mathrm{bp}$ of positive bands (a,c,d,f). In parallel to amplified gene of IGF-I, COX1 gene (cytochrome oxidase I) was tested showing the similar results (the data not shown).

\section{References}

1. (2018) Wikipedia Polymerase chain reaction. https://es.wikipedia. org/wiki/Reacci\%C3\%B3n_en_cadena_de_la_polimerasa\#cite_noteBartlett_\&_Stirling-1

2. (2018) Bio-rad - temperature control.

3. Ahmed SA, Cheah HL, Ravichantar N, Gopinath SB, Tang TH (2016) Evaluation of Palm PCR ${ }^{\mathrm{TM}}$ G1-12 System: a portable battery-operated PCR thermal cycler. Songklanakarin Journal of Science \& Technology 38(4): 343-348.

4. Trojan J, Pan YX, Wei MX, LyA, Shevelev A, et al. (2012) Methodology for anti - gene anti - IGF-I therapy of malignant tumours. Chemother Res Pract.

5. Trojan A, Aristizabal B, Jay LM, Castillo T, Penagos P, et al. (2016) Testing of IGF-I biomarker in an ethical context. Adv Modern Onco Res 2(4).

6. Zumkeller W, Westphal M (2001) The IGF/IGFBP system in CNS malignancy. Mol Pathol 54(4): 227-229.

7. Wong G, Wong I, Chan K, Hsieh Y, Wong S (2015) A Rapid and low-cost PCR Thermal Cycler for low resource settings. Plos ONE 10(7): 1-20.

8. Obrepalska-Steplowska A, Kedzia A, Trojan J, Goździcka-Józefiak A (2003) Analysis of coding and promoter sequences of the IGF-I gene in children with growth disorders presenting with normal level of growth hormone. J Pediatr Endocrinol Metab 16(9): 1267-1275.

9. Quintero G, Restrepo C, Abuchaibe O, Rojas C, Rey JJ, et al. (2018) Cancer Immunogene therapy: Antisense and Triple helix approach. Biomed J Sci \& Tech Res (BJSTR) 2(3). 
ISSN: 2574-1241

DOI: 10.26717/BJSTR.2018.08.001678

Jerzy Trojan. Biomed J Sci \& Tech Res

(C) (P) This work is licensed under Creative

Submission Link: https://biomedres.us/submit-manuscript.php

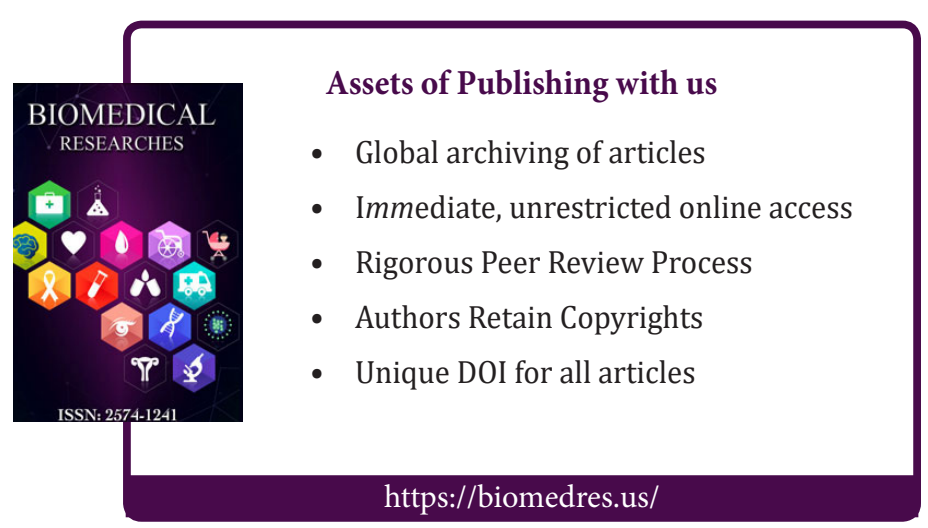

